\title{
Rhabdomyolosis and its pathogenesis
}

\author{
Mei-hua Zhang \\ Department of Pharmacy, First Affiliated Hospital of Zhejiang University School of Medicine, Hangzhou 310006, China
}

Corresponding Author: Mei-hua Zhang,Email: pharmacistzhang@yahoo.com.cn

BACKGROUND: Rhabdomyolysis may cause severe damage to the human body because of acute renal failure, fatal heart rhythm disturbances, hypovolemic shock, disturbances of electrolyte balance, metabolic acidosis, hyperthermia, disseminated intravascular coagulation, etc. Drugs and toxins are the most common factors for the disease. This article aimed to review the prognosis of rhabdomyolysis.

DATA SOURCES: Based on the reported studies of cell and molecular biology, we reviewed the clinical presentations, laboratory findings, and mechanisms of rhabdomyolysis in the Pubmed.

RESULTS: The clinical symptoms of rhabdomyolysis were dependent on the severity of the condition and whether kidney failure develops. Since the necrosis and dissolution of muscle cells, entocytes such as myoglobin, creatine phosphokinase (CPK), electrolytes, proteins and non-protein substances were released into the plasma, the detection of the entocytes may contribute to the early diagnosis of rhabdomyolysis.

CONCLUSION: Despite the etiology of the disease is multifactorial, the potential causes of rhabdomyolysis share the same pathophysiological pathway involving an increase in intracellular calcium.

KEY WORDS: Rhabdomyolysis; Etiology; Pathophysiological pathway

World J Emerg Med 2012;3(1):11-15

DOI: $10.5847 /$ wjem.j.1920-8642.2012.01.002

\section{INTRODUCTION}

Rhabdomyolysis is a condition causing damage to skeletal muscle tissue rapidly. Breakdown products of damaged muscle cells are released into the bloodstream. Laboratory tests have shown that serum creatine phosphokinase (CPK) is elevated in cases of rhabdomyolysis and is accompanied with the high level of serum myoglobin ( Mb). ${ }^{[1]}$ Rhabdomyolysis can cause serious body damage via several mechanisms such as acute renal failure, fatal heart rhythm disturbances, hypovolemic shock, disturbances of electrolyte balance, metabolic acidosis, hyperthermia, disseminated intravascular coagulation, etc. Muscle fiber necrosis may occur as a primary disorder related to inherited or structural abnormalities of muscle cells. In most cases, the necrosis is secondary to an infection, drugs, toxins, an injury, or another external cause. ${ }^{[2]}$ Drugs and toxins, however, are the most common causes. ${ }^{[3]}$ Based on the studies of cell and molecular biology, this article aimed to review the prognosis of rhabdomyolysis.

\section{Clinical presentations}

Although the final diagnosis of rhabdomyolysis is mainly dependent on the laboratory test, we should pay more attention to its clinical presentations. The symptoms of rhabdomyolysis depend on the severity of the condition and whether kidney failure develops. Mild forms of rhabdomyolysis may not cause any muscle symptoms, and its diagnosis is based on abnormal results of blood tests and other problems. Severe rhabdomyolysis is characterized by pain, tenderness, weakness and swelling of the affected muscles. If the swelling is very rapid, as it happens after someone is released from a collapsed building; the movement of fluid from the bloodstream into damaged muscle 
may cause low blood pressure and shock. Other symptoms are nonspecific and result either from the consequences of muscle tissue breakdown or from the condition that led to the muscle breakdown. Release of the components of muscle tissue into the bloodstream causes disturbances in electrolytes, which can lead to nausea, vomiting, confusion, coma or abnormal heart rate and rhythm. The urine may be dark, often described as "tea-colored", due to the presence of myoglobin. Damage to the kidneys may give rise to decreased or absent urine production, usually 12 to 24 hours after the initial muscle damage. ${ }^{[4]}$

Swelling of the damaged muscle occasionally leads to compartment syndrome, i.e. compression of surrounding tissues, such as nerves and blood vessels, in the same fascial compartment, leading to the loss of blood supply and damage or loss of function in part of the body supplied by these structures. Symptoms of this complication include pain or reduced sensation in the affected limb.$^{[5]}$ A second recognized complication is disseminated intravascular coagulation (DIC), a severe disruption in blood clotting that may lead to uncontrollable bleeding. ${ }^{[5]}$

\section{Laboratory findings}

Because of the necrosis and dissolution of muscle cells, entocytes, such as myoglobin (Mb), CPK, electrolytes, protein and non-protein substances, are released into the plasma. Thus the detection of these entocytes may be helpful in the early diagnosis of rhabdomyolysis.

Myoglobin is composed of globin (a polypeptide chain of 135 amino acids) and a molecule of heme. The molecular weight of myoglobin is approximately $18 \mathrm{kD}$, one-fourth of hemoglobin. ${ }^{[6]}$ During rhabdomyolysis, a portion of the myoglobin from skeletal muscle cells enters the plasma. The low binding affinity of serum for myoglobin and the small molecular weight of myoglobin contribute to the increased filtering of the molecule. When the concentration of myoglobin in the preurine exceeds the reabsorbing capacity of glomerular cells, an excessive amount of myoglobulin appears in the urine. The half-life of myoglobin is particularly short, about 2-3 hours. In rhabdomyolysis, the level of myoglobin in the serum increases within 1-3 hours, peaks within 8-12 hours, and then returns to normal within 24 hours after the onset of the injury. Thus, the detection of myoglobin in the blood or urine is specific for the diagnosis of rhabdomyolysis. This is helpful in the early diagnosis of rhabdomyolysis (i.e., within the first 24 hours). ${ }^{[7]}$

Increased level of serum CPK is a marker for the diagnosis of rhabdomyolysis. CPK is active in skeletal muscles, and catalyzes the transportation of one phosphate group from creatinine (CP) to ADP, resulting in ATP and creatinine $(\mathrm{C}){ }^{[8]}$ There are three isoenzymes of CPK: muscle-type creatine phosphokinase (CPK$\mathrm{MM}$ ), myocardial isoenzyme of ccreatine phosphokinase (CPK-MB), and brain-type creatine phosphokinase (CPK-BB). CPK-MM is mainly found in skeletal muscles, but it is less in the myocardium; CPK-MB is mainly seen in the myocardium; CPK-BB is observed in the brain and kidneys. CPK-MM is often increased in rhabdomyolysis. ${ }^{[8]} \mathrm{CPK}$ elevates in the first 12 hours after the onset of rhabdomyolysis, peaks within the first 3 days, and returns to the baseline level at 3-5 days after the injury. The half-life of CPK is 1.5 days. Therefore, CPK and more specifically CPK-MM isoenzyme is a more reliable marker than myoglobin in the diagnosis of muscular damage because it remains at high levels for a longer period compared to serum myoglobin.

During rhabdomyolysis, electrolyte imbalance and hyperkalemia develop. Whereas, hyperkalemia is aggravated by coexistent metabolic acidosis and renal dysfunction, thus causing fatal ventricular arrhythmias. ${ }^{[6]}$ Therefore, some clinical risk factors can be avoided in advance by observation of changes of serum potassium..$^{[9]}$

During the disruption of muscle cells, inorganic and organic phosphoric components are dissolved and a large amount of inorganic phosphorus is released into the plasma, leading to hyperphosphatemia. Hyperphosphatemia causes the deposition of calcium phosphate on the destroyed muscle cells and other tissues, resulting in early hypocalcemia during rhabdomyolysis. During cellular necrosis, calcium, initially combined with muscle cells, is released back into the plasma. Following combination with the secondary hyperparathyroidism that takes place because of early hypocalcemia and high levels of vitamin D (produced in great quantities by the glomerular cells), late hypercalcemia occurs.

In addition, hyperuricemia is observed in rhabdomyolysis. Increased levels of carbonic anhydrase III, heavy-chain myosin fragment and other proteases [e.g. such as lactate dehydrogenase, aspartate aminotransferase], are commonly seen in rhabdomyolysis. Hypoalbuminemia, anemia, and contraction of intravascular volume can also be used for the diagnosis of rhabdomyolysis. 


\section{Mechanisms of rhabdomyolysis Etiology of rhabdomyolysis Balance of intracellular calcium}

The concentration of free ionized calcium in the extracellular space $\left(\mathrm{Ca}^{2+}\right)$ is 10000 times higher than that in the intracellular space. Hence, minimal changes of the $\mathrm{Ca}^{2+}$ permeability in the cellular membrane may result in significant changes in its intracellular concentration and cause unfavorable consequences for the functional integrity of the cell, ${ }^{[10]}$ which has to maintain the balance of intracellular calcium within the normal range. For this purpose, it is equipped with a group of special regulatory proteins including: nonmembrane proteins soluble in the cytoplasm, and transmembrane proteins as regulators of calcium concentration. ${ }^{[10]}$ The transmembrane proteins consist of a series of carrier proteins located either at the plasma membrane of the muscle cell (sarcolemma) or at the membranes of intracellular organelles, notably the sarcoplasmic reticulum and mitochondria. The plasma membrane carrier proteins include $\mathrm{Ca}^{2+}$ channels, $2 \mathrm{Na}^{+} /$ $\mathrm{Ca}^{2+}$ exchanger, and $\mathrm{Ca}^{2+}$ ATPase pump. The $\mathrm{Ca}^{2+}$ channels and the $2 \mathrm{Na}^{+} / \mathrm{Ca}^{2+}$ exchanger facilitate the energy-consuming entrance of $\mathrm{Ca}^{2+}$ into the cytoplasm, whereas the $\mathrm{Ca}^{2+}$ ATPase pump facilitates the energyconsuming transportation of $\mathrm{Ca}^{2+}$ to the extracellular space. ${ }^{[10]}$ In the sarcoplasmic reticulum, the $\mathrm{Ca}^{2+}$ ATPase pump is responsible for the entrance of $\mathrm{Ca}^{2+}{ }^{211]}$ The $\mathrm{Ca}^{2+}$ is brought into the mitochondria with the $\mathrm{Ca}^{2+}$ uniporter, and the release of $\mathrm{Ca}^{2+}$ into the cytoplasm is primarily accomplished by the $2 \mathrm{Na}^{+} / \mathrm{Ca}^{2+}$ exchanger. Despite the fact that the causes of rhabdomyolysis are numerous, the final pathogenetic pathway is commonly characterized by an increase in free ionized calcium in the cytoplasm. The increased $\mathrm{Ca}^{2+}$ initiates a chain of downstream reactions that eventually lead to the destruction of the muscle cell.

\section{Causes of increased concentration of intracellular calcium}

The major causes of increased concentration of intracellular calcium share a common pathogenetic basis involving either energy depletion in the muscle cell or (sarcolemma) rupture of the plasma membrane.

The reduction in energy production is mirrored by a decrease in adenosine triphosphate (ATP) and causes the dysfunction of energy-dependent ion pumps such as $\mathrm{Na}^{+} /$ $\mathrm{K}^{+}$ATPase and $\mathrm{Ca}^{2+}$ ATPase in the sarcolemma as well as in other intracellular membranes. ${ }^{[12]} \mathrm{Na}^{+} / \mathrm{K}^{+}$ATPase pump dysfunction results in an increase in intracellular $\mathrm{Na}^{+}$ concentration. Following an intracellular $\mathrm{Na}^{+}$increase, the cell increases the activity of the $2 \mathrm{Na}^{+} / \mathrm{Ca}^{2+}$ exchanger, which removes the excess intracellular $\mathrm{Na}^{+}$from the cytoplasm by exchanging it with $\mathrm{Ca}^{2+}$, ultimately increasing the concentration of cytoplasmic calcium. As the $2 \mathrm{Na}^{+} / \mathrm{Ca}^{2+}$ exchanger requires energy to function properly, the energy deficit of the cell is accentuated. ${ }^{[13]}$ In this situation, $\mathrm{Ca}^{2+}$ ATPase releases any surplus of intracellular $\mathrm{Ca}^{2+}$ into the extracellular space, turns to be dysfunctional, and further increases $\mathrm{Ca}^{2+}$.

The sarcoplasmic reticulum and mitochondria constitute the most important intracellular depots of free ionized calcium. Their role is to deposit the excess cytoplasmic calcium so that its concentration in the cytoplasm can be kept at a low level. As mentioned, these organelles are equipped with special mechanisms of transmembrane calcium transportation $\left(\mathrm{Ca}^{2+}\right.$ ATPase and $\mathrm{Ca}^{2+}$ uniporter) that hydrolyze ATP for proper functioning. ${ }^{[14,15]}$ The decreased energy production in rhabdomyolysis hinders the function of the organelles, thereby sustaining high levels of $\mathrm{Ca}^{2+}$.

Several factors directly affect the membrane of muscle cell and cause interruption of its continuity, resulting in a massive influx of extracellular calcium into the cytoplasm driven by its chemical gradient. In addition, the progressive damage of the sarcoplasmic reticulum and mitochondria during cellular death promotes the release of stored calcium ions into the cytoplasm. ${ }^{[16]}$ This phenomenon leads to the overloading of the muscle cell with $\mathrm{Ca}^{2+}$. Once $\mathrm{Ca}^{2+}$ exceeds a critical limit, the cascade of cellular death is activated. ${ }^{[17]}$

\section{Pathophysiological mechanisms of rhabdomyolysis Activation of phospholipase $A_{2}$}

Increased concentration of $\mathrm{Ca}^{2+}$ activates phospholipase $\mathrm{A}_{2}$ and various neutral proteases (e.g., calpain) ${ }^{[18]}$ that degrade the cellular phospholipid membranes (e.g., plasma membrane, mitochondrial membrane) and various intracellular organelles. Following the enzymatic dissolution of membrane phospholipids, the resultant lysophosphatides and free fatty acids lead to direct toxic damage to the sarcolemma and other intracellular membranes or dysfunction of cell membrane carrier proteins and finally to the entry of $\mathrm{Ca}^{2+}$ into the cytoplasm.

\section{Persistent contractility of muscular cell}

Increased concentration of $\mathrm{Ca}^{2+}$ keeps muscle cell contract continuously, resulting in severe ATP depletion and progressive exhaustion of the cellular energy reserves. 


\section{Mitochondrial dysfunction}

The rapid increase of $\mathrm{Ca}^{2+}$ concentration contributes to an increase of $\left[\mathrm{Ca}^{2+}\right] \mathrm{m}$ in mitochondrial calcium because of its chemical gradient between the cytoplasm and mitochondrion. As mentioned above, the mitochondrion acts as a "safety reservoir" that succeeds in depositing a large quantity of $\mathrm{Ca}^{2+}$ when its concentration in the cytoplasm is excessively increased. ${ }^{[19]}$ In this way, the cell saves time in order to confront the actual cause of $\left[\mathrm{Ca}^{2+}\right] \mathrm{c}$ increase. If the cause persists for a long time, the overloading of the mitochondrion with $\mathrm{Ca}^{2+}$ adversely affects its structural and functional integrity (e.g., dysfunction of oxidative phosphorylation), eventually impairing the production of ATP. Such a reduction in ATP worsens the dysfunction of $\mathrm{Ca}^{2+}$ carrier proteins in the sarcolemma and intracellular organelles, thereby initiating a self-perpetuating, vicious circle.

\section{Free radical production-oxidative stress}

Increased mitochondrial calcium $\left[\mathrm{Ca}^{2+}\right] \mathrm{m}$ leads to increased production of reactive oxygen species (ROS, e.g. $\mathrm{O}_{2} \bullet, \mathrm{OH} \bullet, \mathrm{H}_{2} \mathrm{O}_{2}$ ). ${ }^{[20]}$ Human body has its own powerful endogenous antioxidant systems, such as superoxide dismutase, catalase and glutathione. ${ }^{[21]}$ When the endogenous antioxidant capacity of the system is weakened, body cells will suffer from ROS attack, resulting in oxidative stress. ${ }^{[2]}$ ROS oxidates various biomolecules of the cell such as proteins, lipids and nucleic acids, leading to structural and functional impairment of the cell. Because proteins and lipids are basic structural components of biological membranes and intracellular organelles, their destruction influences the integrity of the sarcolemma and intracellular membranes as well as the function of various intracellular organelles such as mitochondria and sarcoplasmic reticulum. Ultimately, cytoplasmic calcium increases. Moreover, ROS induce mutations in both nuclear and mitochondrial DNA. The modification of nuclear DNA leads to functional disorganization of the muscle cell, whereas mutations of mitochondrial DNA which contains the coding sequences for the respiratory chain proteins leads to structural and functional degeneration of the electron transport system, resulting in reduced ATP production. It is reported that myoglobin causes oxidative stress, increase of NO production, and dysfunction of kidney mitochondria. ${ }^{[23]}$

\section{Cell death}

The results of the aforementioned complex and selfreinforcing reactions can cause the lysis of muscle cells and the release of their toxic content into the extracellular space. The concentration of toxic substances in the microenvironment of the muscle cell causes damage to the adjacent capillaries, inducing local edema, increase of intracompartmental pressure, and regional ischemia. The ischemia further augments the energy depletion, resulting in damage of more capillaries. The circulating leukocytes adhere to the damaged capillaries, become activated, and transmigrate to the damaged muscle cells. Thus released ROS and proteolytic enzymes from the cells aggravate cellular impairment. $^{[24,25]}$

\section{Conclusion}

Although the etiology of rhabdomyolysis is multifactorial, their potential causes share the same pathophysiological pathway involving an increased concentration of intracellular calcium. Since rhabdomyolysis is critical in clinical practice, it is important for physicians to recognize its pathogenesis, clinical manifestations, and laboratory data, and to make a timely decision for the prevention or treatment of serious complications of the disease.

Funding: None.

Ethical approval: None.

Conflicts of interest: The author has no financial or other conflicts of interest regarding this article.

Contributors: Zhang MH is involved in study design, data collection, data analysis, and drafting and revision of the manuscript.

\section{REFERENCES}

1 David WS. Myoglobinuria. Neurol Clin 2000; 18: 215-243.

2 Warren JD, Blumbergs PC, Thompson PD. Rhabdomyolysis: a review. Muscle Nerve 2002; 25: 332-347.

3 Zink BJ. The Biology of Emergency Medicine: what have 30 years meant for Rosen's original concepts? Acad Emerg Med 2011; 18: 301-304.

4 Sauret JM, Marinides G, Wang GK. Rhabdomyolysis. Am Fam Physician 2002; 65: 907-912.

5 Warren JD, Blumbergs PC, Thompson PD. Rhabdomyolysis: a review. Muscle \& Nerve 2002; 25: 332-347.

6 Singh D, Chander V, Chopra K. Rhabdomyolysis. Methods Find Exp Clin Pharmacol 2005; 27: 39-48.

7 Melli G, Chaudhry V, Cornblath DR. Rhabdomyolysis: an evaluation of 475 hospitalized patients. Medicine 2005; 84 : 377-385.

8 Schlattner U, Tokarska-Schlattner M, Wallimann T. Mitochondrial creatine kinase in human health and disease. Biochim Biophys Acta 2006; 1762: 164-180. 
9 Cecil KM, Brubaker CJ, Adler CM, Dietrich KN, Altaye M, Egelhoff JC, et al. Decreased brain volume in adults with childhood lead exposure. PLoS Med 2008; 5: e112.

10 Guerini D, Coletto L, Carafoli E. Exporting calcium from cells. Cell Calcium 2005; 38: 281-289.

11 Moller JV, Nissen P, Sorensen TL, le Maire M. Transport mechanism of the sarcoplasmic reticulum $\mathrm{Ca}^{2+}$-ATPase pump. Curr Opin Struct Biol 2005; 15: 387-393.

12 Clausen $\mathrm{T} . \mathrm{Na}^{+}-\mathrm{K}^{+}$pump regulation and skeletal muscle contractility. Physiol Rev 2003; 83: 1269-1324.

13 Vanholder R, Sever MS, Erek E, Lameire N. Rhabdomyolysis. J Am Soc Nephrol 2000; 11: 1553-1556.

14 Pfeiffer DR, Gunter TE, Eliseev R, Broekemeier KM, Gunter KK. Release of $\mathrm{Ca}^{2+}$ from mitochondria via the saturable mechanisms and the permeability transition. IUBMB Life 2001; 52: 205-212.

15 Campanella M, Pinton P, Rizzuto R. Mitochondrial $\mathrm{Ca}^{2+}$ homeostasis in health and disease. Biol Res 2004; 37: 653-660.

16 Stark G. Functional consequences of oxidative membrane damage. J Membr Biol 2005; 205: 1-16.

17 Rizzuto R, Pinton P, Ferrari D, Chami M, Chami M, Szabadkai $\mathrm{G}$, et al. Calciumand apoptosis: facts and hypotheses. Oncogene 2003; 22: 8619-8627.

18 Smith MA, Reid MB. Redox modulation of contractile function in respiratory and limb skeletal muscle. Respir Physiol
Neurobiol 2006; 151: 229-241.

19 Campanella M, Pinton P, Rizzuto R. Mitochondrial $\mathrm{Ca}^{2+}$ homeostasis in health and disease. Biol Res 2004; 37: 653-660.

20 Brookes PS, Yoon Y, Robotham JL, Anders MW, Sheu SS. Calcium, ATP, and ROS: a mitochondrial love-hate triangle. Am J Physiol Cell Physiol 2004; 287: C817-833.

21 Jezek P, Hlavata L. Mitochondria in homeostasis of reactive oxygen species in cell, tissues, and organism. Int J Biochem Cell Biol 2005; 37: 2478-2503.

22 Touyz RM. Reactive oxygen species as mediators of calcium signaling by angiotensin II: implications in vascular physiology and pathophysiology. Antioxid Redox Signal 2005; 7: 13021314.

23 Egor YP, Anastasia AC, Irina BP, Isaev NK, Zorov DB. Myoglobin causes oxidative stress, increase of NO production and dysfunction of kidney's mitochondria. Biochimica Biophysica Acta 2009; 1792: 796-803.

24 Le Bras M, Clement MV, Pervaiz S, Brenner C. Reactive oxygen species and the mitochondrial signaling pathway of cell death. Histol Histopathol 2005; 20: 205-219.

25 Wardle EN. Cellular oxidative processes in relation to renal disease. Am J Nephrol 2005; 25: 13-22.

Received July 12, 2011 Accepted after revision November 25, 2011 